\title{
Better online tool for continuing professional development
}

A

fter more than five years of planning, testing and coding, The College of Family Physicians of Canada (CFPC) has launched Mainpro+, an updated, enhanced and streamlined version of its continuing professional development (CPD) support program.

"It's more sleek and easy to use," says Amy Outschoorn, CFPC's director of continuing professional development.

Mainpro+ builds on the college's original software program, so the learning curve for family doctors will not be onerous. It uses new and simplified categories - group learning, self-learning and assessment - that allow doctors to earn credit for more practice activities. There is also a new credit-reporting platform for entering CPD activities and a revamped dashboard that provides a snapshot of professional development over the past five years.

The rules around certification have changed as well. "We hope to increase the quality of programs. One half of all programs [reported] must be certified," says Dr. Jamie Meuser, CFPC's executive director of professional development and practice support.

In addition, notes Meuser, family doctors are now being asked to report on the impact of an activity on their practice. "It will give us a lot more information on how successful we were in what we intended to do."

Family doctors, who must complete and report a minimum of 250 Mainpro+ credits in a five-year period, will also discover an expanded list of roles for any educational activity, including medical expert, communicator and collaborator.

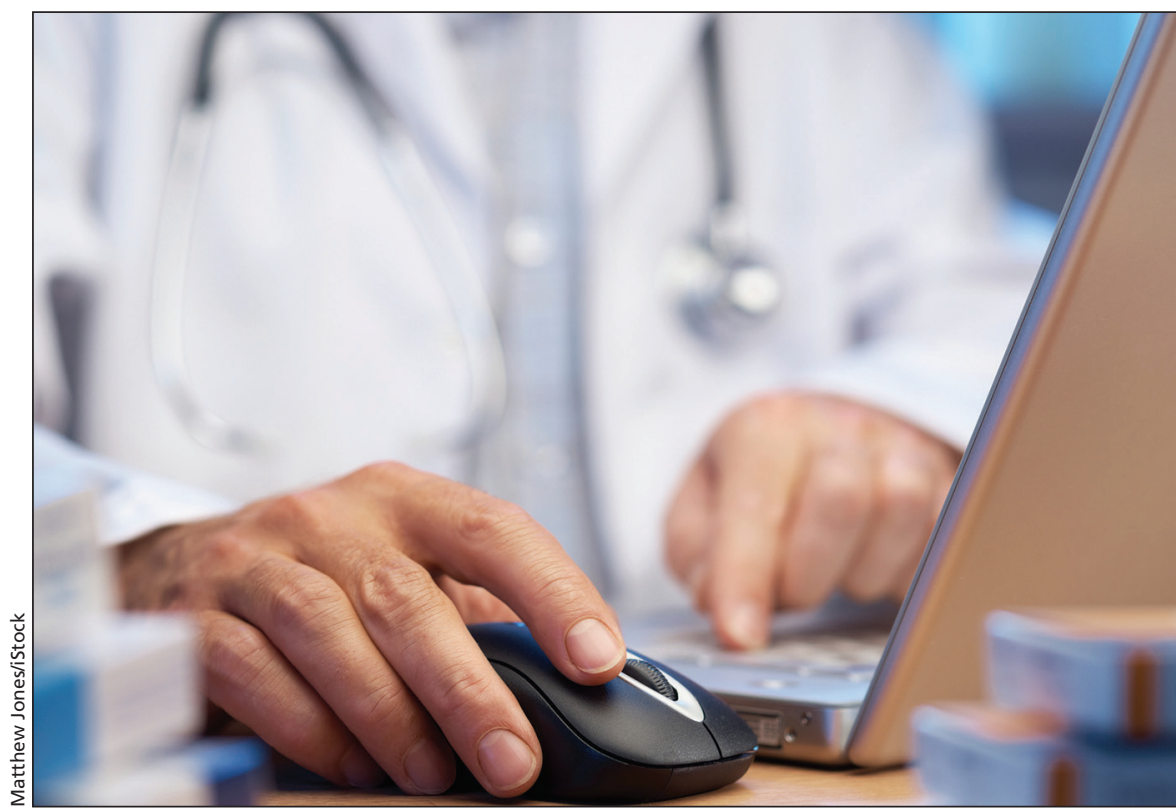

A revamped online tool makes it easier for family doctors to earn continuing professional development credits.

What doctors won't find with Mainpro+ is a lot of flash and fanfare. "We wanted to make it as broadly useful as possible," says Meuser. The college is now working on an app.

It has been two decades since the college first introduced Mainpro (a shortened form of "maintenance" and "proficiency"). "The world of continuing professional development for physicians has changed," says Meuser. "The way physicians learn and the things they need to learn have also changed."

He points out that the distinction that once existed between practising and training has disappeared. "We now know that most of the impactful learning people do comes from their practice."

The CFPC's new online program continues to serve two key functions. It provides CPD participation guidelines and standards and enables family physicians to conveniently track and monitor their participation in continuing professional development. It also relies on a rigorous peer-review certification process to ensure programming quality.

Although it is too early to say whether family physicians across the country are finding Mainpro+ easier to use and improved, early signs are positive. A scheduled appointment to walk the CFPC's board of directors through the new program was cancelled after members tried the system for themselves and had no questions. "That was a measure of success," says Outschoorn. donalee Moulton, Halifax, NS

CMAJ 2016. DOI:10.1503/cmaj.109-5302 